\title{
Molecular and Phenotypic Characterization for Cold Tolerance in Rice (Oryza sativa L.)
}

\author{
P S Biswas ${ }^{1 *}, \mathrm{H}_{\text {Khatun }}{ }^{1}$ and M Anisuzzaman ${ }^{1}$
}

\begin{abstract}
Cold stress affects growth and development of rice plants from germination to reproductive stages. Thirty breeding lines/varieties including tolerant and susceptible check varieties were evaluated for cold tolerance at seedling and reproductive stage using artificially induced low temperature situations to understand the genetic relationship among them and to identify promising donors for cold tolerance. Three breeding lines, BR8253-9-3-4-3, IR77497-31-2-3-1and IR2266-42-6-2 demonstrated higher cold tolerance for the seedling stage (LD score <3.0). Molecular analysis revealed $68 \%$ genetic similarity among the genotypes. On average $64 \%$ of the breeding lines shared common alleles at any given locus ranging from 27\% (RM22870) to 97\% (RM186). UPGMA dendrogram showed that majority of the breeding lines showing 4-5 degrees of LD were grouped together. Two breeding lines, BR8258-7-1-5-2B2 and BR8258-7-1-5-2B3 having 86\% common alleles showed low leaf discoloration (LD: 4) at seedling stage coupled with relatively low reduction in spikelet fertility (45.8\% and $48.1 \%$ ) and grain yield $(43.3 \%$ and $39.1 \%)$. The gene diversity and PIC value revealed that seven SSR loci (RM1282, RM600, RM5349, RM6972, RM5847, RM5911, and RM511) might be the best markers to differentiate between tolerant and susceptible genotypes at reproductive stage. The breeding lines with tolerance to cold stress at the seedling and the reproductive stages identified from this study, and the SSR markers mentioned above could be useful for developing cold tolerance rice.
\end{abstract}

Key words: Cold tolerance, leaf discoloration score, spikelet fertility, SSR marker, genetic diversity

\section{INTRODUCTION}

Rice is the staple food for more than half of the world's population providing $21 \%$ of the global per capita energy and $15 \%$ of per capita protein intake (Maclean et al., 2002). Although originating in swampy areas of the tropics, rice is now grown globally in diverse ecologies and thus suffers a wide range of abiotic stresses. Low-temperature stress (LTS) or cold is a worldwide problem limiting rice yield. Rice crops normally suffer from two types of cold stresses; at the early vegetative stage of rice crop, LTS restrains seedling establishment and plant growth and development; at the reproductive stage, cold induces low fertility and poor grain filling (Andaya and Tai, 2006). In Bangladesh, around 2 million hectare of rice area becomes affected by low temperature stress or cold during the winter season causing seedling mortality in some years up to $90 \%$ when ambient temperature goes below $10^{\circ} \mathrm{C}$ and thereby increases cultivation cost. Worse, a bad cold spell during the reproductive phase of the rice crop sometimes causes partial to total loss of the crop due to the failure of the seed set. Yoshida (1980) reported that upon exposure to the temperature below $10^{\circ} \mathrm{C}$ for 5 6 days at early vegetative stage rice plant gets yellowing, stunting, reduced growth and dies ultimately due to wilting. The reproductive stage, particularly at booting stage of rice plants is the most sensitive stage to LTS of $15^{\circ}$ $-20^{\circ} \mathrm{C}$ (Yoshida 1980). Complete failure of seed setting may occur upon exposure to LTS below $17^{\circ} \mathrm{C}$. In the winter season in Bangladesh, ambient temperature usually goes below $10^{\circ} \mathrm{C}$ at majority of the Northern districts, which 
causes yellowing and stunted growth of Boro rice seedlings that ultimately turns into seedling mortality. On the other hand, reproductive stage of early grown Boro rice varieties in the haor areas becomes affected with low temperature which causes spikelet sterility up to $100 \%$ in some years (Rashid and Yasmeen, 2017; Kabir et al., 2015).

Rice genotypes differ considerably in cold tolerance (Mackill and Lei, 1997). Indica rices that are widely grown in South Asia, are very much susceptible to cold stress. The development of high-yielding, cold-tolerant cultivars is the most effective way to overcome the problem of LTS. The progress to the improvement of cold tolerance in rice that has so far been made is based on phenotypic selection and conventional breeding strategy (Unkovich, 2008). However, considerable efforts have been taken by different groups of researchers (Qian et al., 2000; Misawa et al., 2000; Andaya and Mackill, 2003; Han et al., 2004; Han et al., 2007; Zhang et al., 2005; Lou et al., 2007; Jiang et al., 2008; Baruah et al., 2009; Ji et al., 2010; Iwata et al., 2010) to genetically dissect rice cold tolerance using DNA markers, which has resulted into the discovery and mapping of many quantitative trait loci (QTLs) associated with cold tolerance. Two major QTLs for cold tolerance (CT), qCTS4 and qCTS12, have been fine-mapped onto rice chromosome 4 and the short arm of chromosome 12, respectively (Andaya and Tai, 2006 and Andaya and Tai, 2007). Kim et al. (2014) identified one candidate gene encoding calmoduline-binding transcription activator (CAMTA) from a japonica cultivar Jinbubyeo responsible for cold tolerance at seedling stage. From a map based cloning study with a cold tolerant variety Norin-PL8, Saito et al. (2010) showed that a gene encoding F-Box protein on chromosome 4 confers cold tolerance at reproductive stage. Recently, Sun et al. (2018) reported that LOC_Os06g39750 was strongly associated with seed setting under cold water irrigation condition of $17^{\circ} \mathrm{C}$. Unfortunately, results from these genetic studies have not yet been directly fruitful for marker-assisted selection to develop improved rice varieties tolerant to cold stress owing to possible epistasis and gene $\times$ environment interactions associated with the identified QTLs (Hospital, 2009). Furthermore, most of the reported QTLs are of japonica origin. Improvement of indica rice using QTLs from japonica donors restrains by linkage drag of undesired traits like spikelet sterility, low tillering (Ribaut and Hoisington, 1998; Salina et al., 2003), although these can be resolved by using high resolution marker system for background recovery, which may entail huge expense in line development. Contrary, haplotypes of these genes in indica background might be a better option in this regard. Therefore, molecular characterization and phenotypic screening of indica varieties, breeding lines or germplasm for cold tolerance could reveal their usefulness in utilization of genetic improvement of existing varieties. Thus in this study, we investigated genetic diversity among the breeding lines using SSR marker to identify potential elite indica cold tolerant donor to use in the breeding programme for the developing cold tolerant rice.

\section{MATERIALS AND METHODS}

A set of 594 advanced breeding lines derived from the crosses between different genetically diverged parents were-evaluated as the initial materials for cold stress tolerance at seedling and reproductive stages. BR1 and BR18 were used as the susceptible and tolerant check varieties. A subset of 22 genotypes selected from the initial screening against LTS was used in further evaluation for cold tolerance at both seedling and reproductive stages (Table 1). This subset of genotypes was also used in genotyping with SSR markers to assess genetic diversity among them. 
Table 1. The breeding lines used in phenotypic evaluation for cold tolerance and genetic diversity analysis.

\begin{tabular}{|c|c|c|}
\hline Designation & Parentage & Origin \\
\hline BR8264-1-1-3B2-HR4 & BR7166-5B-4/YUNLUN63 & Bangladesh \\
\hline BR7840-54-3-2-1 & IR75382-32-2-3-3/ BR7166-4-5-3-2-5-5B1-92 & Bangladesh \\
\hline BR7840-54-5-3-4 & IR75382-32-2-3-3/ BR7166-4-5-3-2-5-5B1-92 & Bangladesh \\
\hline BR7683-30-3-3-4 & BRRI dhan32/BR7166-4-5-3-2-5-8B2 & Bangladesh \\
\hline IR83294-9-1-3-2-3-Gaz1 & Daesanbyeo/IR56664-44-5-1 & IRRI \\
\hline BR8427-2-3-2 & BR7166-5B-5/IR73001-13-2-2-2 & Bangladesh \\
\hline BR8260-16-2-3-1 & BR7166-5B-4/ BR7166-5B-1-RAN1 & Bangladesh \\
\hline BR8261-19-1-5-1 & BR7166-5B-4/BRRI dhan29 & Bangladesh \\
\hline BR8331-13-3-1-3 & BR7305-21-6-1/BRRI dhan45//BRRI dhan45 & Bangladesh \\
\hline BR8260-7-3-1-1B1 & BR7166-5B-4/BR7166-5B-1-RAN1 & Bangladesh \\
\hline BR8261-19-1-1-3 & BR7166-5B-4/BRRI dhan29 & Bangladesh \\
\hline BR8258-7-1-5-2B3 & IR71780-1-1-3-2/BR7166-4-5-3-2-5B1-6-3//BRRI dhan29 & Bangladesh \\
\hline BR8261-19-5-2-4 & BR7166-5B-4/BRRI dhan29 & Bangladesh \\
\hline A69-1 & BG94-1/POKKALI & Srilanka \\
\hline IR83294-9-1-3-2-3-P1 & Daesanbyeo/IR56664-44-5-1 & IRRI \\
\hline BR7840-2-1-1-P2 & IR75382-32-2-3-3/ BR7166-4-5-3-2-5-5B1-92 & Bangladesh \\
\hline BR8253-9-3-4-3 & BR7305-21-6-1/ BRRI dhan29// BR7305-21-6-1 & Bangladesh \\
\hline BR8253-46-7-2-1B1 & BR7305-21-6-1/ BRRI dhan29// BR7305-21-6-1 & Bangladesh \\
\hline BR8257-10-1-1-2 & IR71780-1-1-3-2/BR7166-4-5-3-2-5B1-6-3// TCN58 & Bangladesh \\
\hline BR8258-7-1-5-2B2 & IR71780-1-1-3-2/BR7166-4-5-3-2-5B1-6-3//BRRI dhan29 & Bangladesh \\
\hline BR8260-7-3-4-1B2 & BR7166-5B-4/BR7166-5B-1-RAN1 & Bangladesh \\
\hline BR7988-10-4-3-2 & BR6840-3-4-1/Tep Hanh 170DB & Bangladesh \\
\hline IR77496-31-2-1-3-1 & IR64680-81-2-2-1-3/IR68077-82-2-2-2-3 & IRRI \\
\hline IR2266-42-6-2 & IR1529-123-1/GIZA173 & IRRI \\
\hline BR1 (Sus. Ck) & IR532-1-176 (IR262-24-3/TKM6) & IRRI \\
\hline BR17 (MT. Ck) & Kn-1B-361-1-8-6-10 (Zerak/IR8) & Indonesia \\
\hline BR18 (T. Ck) & B541-B-Kn-22-7-2 (Pelita1-1/IR1108-2) & Indonesia \\
\hline BRRI dhan28 (Sus. Ck) & BR6 (IR28)/Purbachi & Bangladesh \\
\hline BRRI dhan29 (Sus. Ck) & BG90-2/BR51-46-5 & Bangladesh \\
\hline BRRI dhan55 (MT. Ck) & IR73678-6-9-B (IR64/ Oryza rufipogon) & IRRI \\
\hline
\end{tabular}

Sus. $\mathrm{ck}=$ Susceptible check, MT ck = Moderately tolerant check, T. $\mathrm{ck}=$ Tolerant check.

Evaluation of cold tolerance at the seedling stage

The breeding lines were evaluated under artificial cold stress condition of $13^{\circ} \mathrm{C}$ using cold-water irrigation in a water tank as described in Khatun et al. (2016). Briefly, 10 seedlings of each breeding lines/varieties were raised in 1-row plots spaced at $3.0 \mathrm{~cm}$ in the flat bottom plastic trays $(60 \mathrm{~cm} \times 30 \mathrm{~cm} \times 2.5$ $\mathrm{cm}$ ) filled with gravel and crop residue free fertilized soil. The experiment was established following randomized complete block design with three replications. Forty-five entries along with two check varieties were grown at each tray. Same set of entries were grown in three trays with full randomization to consider as three blocks. BR18 and BR1 were grown as the tolerant and susceptible check varieties (Khatun et al., 2016), respectively at every after 15 breeding lines in the trays. After seeding, a 
thin layer of fine granular soil was used to cover the germinating seeds. The seedlings were allowed to grow at ambient temperature. At 3-leaf stage (approximately 12 - 15 days after seeding), the plastic trays were placed in the cold water tank pre-set at $13^{\circ} \mathrm{C}$. Sensitivity to cold stress was recorded using an arbitrary leaf discoloration (LD) scores (1 to 9) as described in Biswas et al. (2017). LD scores were recorded at seven days after cold treatment or when the susceptible check variety (BR1) died. A subset of 24 genotypes selected from the initial cold screening was evaluated thrice with six check varieties for confirmation of seedling stage cold tolerance.

\section{Evaluation of cold tolerance at the reproductive stage}

Twenty-four genotypes along with six check varieties were evaluated for the reproductive stage cold tolerance using controlled temperature in a growth chamber (Dian Corp. Inc, Korea). In this experiment, 25-day-old six seedlings of each genotype were transplanted individually in earthen pot in a circular fashion. Each genotype was transplanted in six pots. The plants were grown in ambient temperature until the meiotic phase of the reproductive stage triggers. Growing tillers from each plant were clipped off at alternate day to allow only the main culm to grow. Three pots out of six of each genotype were placed in the growth chamber adjusted at $15^{\circ} \mathrm{C}$ with 11/13 hours day (3000 lux)/night period and $60 \%$ relative humidity. Other three pots were kept at ambient temperature as control. After 10 days of cold treatment, the pots were further placed at ambient temperature until the plants get maturity. Days to heading, culm length, spikelet fertility, grain yield and panicle exertion were recorded from both treated and control plants. Reduction in percentage of the phenotypic value of a trait from a treated plant was estimated over a control plant. This experiment was repeated twice for further confirmation of cold response.

\section{SSR genotyping}

Thirty breeding lines/varieties including six check varieties were evaluated with 50 SSRs markers. The SSRs were evenly distributed over all 12 chromosomes. DNA was extracted from young leaves tissues of 8-week-old plants using a modified CTAB miniprep method (Virk et al., 1995). PCR analysis was performed in $10 \mu \mathrm{l}$ reactions containing $50 \mathrm{ng}$ of DNA template, $1 \mu \mathrm{l}$ 10X TB buffer (containing 200 $\mathrm{mM}$ Tris- $\mathrm{HCl} \mathrm{pH} 8.3,500 \mathrm{mM} \mathrm{KCl}, 15 \mathrm{mM}$ $\left.\mathrm{MgCl}_{2}\right), 1 \mu \mathrm{l}$ of $1 \mathrm{mM} \mathrm{dNTP}, 0.50 \mu \mathrm{l}$ each of 5 $\mu \mathrm{M}$ forward and reverse primers and $0.2 \mu \mathrm{l}$ of Taq DNA polymerase $(5 \mathrm{U} / \mu \mathrm{l})$ using thermal cycler. After initial denaturation for $5 \mathrm{~min}$ at $94^{\circ} \mathrm{C}$, each cycle comprises $30 \mathrm{sec}$ denaturation at $94^{\circ} \mathrm{C}, 30 \mathrm{sec}$ min annealing at $55^{\circ} \mathrm{C}$, and 30 sec extension at $72^{\circ} \mathrm{C}$ with a final extension for $7 \mathrm{~min}$ at $72^{\circ} \mathrm{C}$ at the end of 35 cycles. The PCR products were separated by electrophoresis on $6 \%$ polyacrylamide. The gels were stained in $0.5 \mathrm{mg} / \mathrm{ml}$ Ethidium bromide and DNA bands were visualized under UV light using a gel documentation system and saved as jpeg format. Allele scoring was performed considering the relative position of the bands in the gel images compared to the position of parental bands.

\section{Phenotypic and molecular data analysis}

The mean, range and standard deviation of LD scores were calculated using Microsoft excel 2010. Percent reduction in different growth trait was calculated using the formula given as, $\%$ reduction $=\frac{\text { Traits of control }- \text { traits of treatment }}{\text { Traits of control }} \times 100$

Molecular weight for allele specific bands of the SSRs was measured using Alpha Ease FC5.0. Summary statistics, including number of alleles per locus, major allele frequency and Polymorphic information content (PIC) values were determined using Power Marker version 3.25 (Liu and Muse, 2005) based on the formula developed by Anderson et al. (1993)

$$
\mathrm{PICi}=1-\sum_{j=1}^{n} P^{2}{ }_{i j}
$$

where, $P_{i j}$ is the frequency of the $j^{\text {th }}$ allele for the $i^{\text {th }}$ marker and is summed over $n$ alleles. 
The genetic distance was calculated using Nei distance (Nei and Takezaki, 1983). The similarity matrix was calculated with the Simqual sub-programme using the Dice coefficient (Dice, 1945) and subjected to cluster analysis by unweighted pair group method for arithmetic mean (UPGMA) and a dendrogram was generated using the programme NTSYSpc (Rohlf, 2002).

\section{RESULTS}

\section{Cold tolerance at the seedling stage}

Leaf discoloration is an important trait for discriminating breeding population under LTS and to isolate tolerant lines/progenies from intolerant one. LD scores of 594 breeding lines ranged from 1 to 9 with an average value of 6.49 and standard deviation of 1.69 , while the susceptible (BR1) and tolerant (BR18) check varieties had LD scores ranging from 7-9 with 0.69 SD (standard deviation) and 1-4 with 0.89 SD, respectively (Table 2). A subset of 22 genotypes showing strong tolerance (LD: 1-3) to cold stress in the initial cold screening experiment along with three susceptible check varieties (BR1, BRRI dhan28 and BRRI dhan29), three tolerant check varieties (tolerant: BR18, moderately tolerant: BR17 and BRRI dhan55) and two IR lines, which showed strong tolerance to cold stress at seedling stage in a study reported by BRRI (2013), were used in the confirmatory cold screening. The results showed wide range of variation among the genotypes in average LD score (3.2 to 8.4). The lowest average LD score was obtained with IR77496-31-2-1-3-1 (3.2) followed by IR2266-426-2 (3.4), BR8257-10-1-1-2 (3.4), BR18 (3.4) and the highest LD was with BR1 (8.4) followed by BRRI dhan28 (7.3), BR17 (5.7). Out of 30 genotypes, twelve showed LD values less than 4, while another 12 genotypes showed LD values ranging from 4.0 to 5.0 (Table 3 ).

\section{Cold tolerance at the reproductive stage}

Upon exposure to LTS, various genotypic responses in different cold related traits at the reproductive stage were observed (Table 4). Heading delays (delay in 50\% flowering than the control) due to cold stress was observed in the treated plants ranging from 2 - 12 days (Mean: 9). Reductions in culm length, spikelet fertility and yield varied from $4.5-43.1 \%$ (average: $17.7 \%$ ), 48.1 - 88.4\% (average: 69.9\%) and $39.1-91.8 \%$ (average: $75.4 \%$ ), respectively (Table 4). Panicle exertion is another important trait determining cold tolerance. The genotypes under cold stress showed variable response to this trait ranging from $1-7$ with an average value of 4.6. Heading delays in cold stress compared to control was five days or less than five days in 2 genotypes (BR18 and BR8331-13-3-1-3) and $10-12$ days in 12 genotypes. Culm length was reduced by more than $30 \%$ in six genotypes and less than $10 \%$ in five genotypes. The maximum reduction in culm length was observed with BR7683-30-3-3$4(43.1 \%)$ followed by IR83294-9-1-3-2-3-Gaz1 $(42.9 \%)$, while the least reduction was observed with BR8260-16-2-3-1 (4.5\%) followed by BR8261-19-5-2-4 (5\%), BR7840-2-11-P1 (5.0\%), BR7840-2-1-1-P1 (5.4\%), BR8264-11-3B2-HR4 (6.5\%), BR8253-46-7-2-1B1 (8.1\%) and thereafter increasing (Table 5). Although nearly $50 \%$ of the genotypes had good panicle exertion, but spikelet fertility and yield/panicle were reduced severely in most of the genotypes due to cold stress compared to the plants grown under ambient temperature. Under cold stress BR8258-7-1-52B2 showed the highest panicle yield coupled with comparatively higher seed set percentage (Table 6). 
Table 2. Leaf discoloration response of 594 breeding lines/varieties to $13^{\circ} \mathrm{C}$ cold water treatment at seedling stage.

\begin{tabular}{lllr}
\hline \multirow{2}{*}{ Genotype } & \multicolumn{3}{c}{ Leaf discoloration score } \\
\cline { 2 - 4 } & Range & Average & SD $(\mathrm{n}=\mathrm{x})$ \\
\hline Breeding line & $1-9$ & 6.49 & $1.69(\mathrm{n}=594)$ \\
BR1 (Susceptible check) & $7-9$ & 8.6 & $0.69(\mathrm{n}=19)$ \\
BR18 (Tolerant check) & $1-4$ & 2.5 & $0.89(\mathrm{n}=19)$ \\
\hline
\end{tabular}

Table 3. Leaf discoloration responses of 30 breeding lines/varieties to $13^{\circ} \mathrm{C}$ cold water treatment at seedling stage.

\begin{tabular}{|c|c|c|c|c|}
\hline \multirow{2}{*}{ Designation } & Batch 1 & Batch 2 & Batch 3 & \multirow{2}{*}{ Average } \\
\hline & $\operatorname{Av} \pm \operatorname{SD}(n=2)$ & $\mathrm{Av} \pm \mathrm{SD}(\mathrm{n}=4)$ & $\operatorname{Av} \pm S D(n=3)$ & \\
\hline BR8264-1-1-3B2-HR4 & $6.0 \pm 1.4$ & $3.0 \pm 1.2$ & $2.3 \pm 1.15$ & 3.8 \\
\hline BR7840-54-3-2-1 & $6.0 \pm 1.4$ & $5.0 \pm 1.9$ & $2.3 \pm 1.15$ & 4.4 \\
\hline BR7840-54-5-3-4 & $4.0 \pm 1.4$ & $6.0 \pm 1.1$ & $2.3 \pm 1.15$ & 4.1 \\
\hline BR7683-30-3-3-4 & $3.5 \pm 2.1$ & $5.7 \pm 0.8$ & $2.3 \pm 1.15$ & 3.8 \\
\hline IR83294-9-1-3-2-3-Gaz1 & $6.0 \pm 1.4$ & $5.0 \pm 0.0$ & $2.3 \pm 1.15$ & 4.4 \\
\hline BR8427-2-3-2 & $6.0 \pm 1.4$ & $5.7 \pm 1.2$ & $3.7 \pm 1.15$ & 5.1 \\
\hline BR8260-16-2-3-1 & $6.0 \pm 1.4$ & $5.3 \pm 1.6$ & $3.7 \pm 1.15$ & 5.0 \\
\hline BR8261-19-1-5-1 & $5.0 \pm 0.0$ & $4.0 \pm 1.1$ & $4.0 \pm 1.73$ & 4.3 \\
\hline BR8331-13-3-1-3 & $5.0 \pm 1.4$ & $4.2 \pm 0.9$ & $4.0 \pm 1.73$ & 4.4 \\
\hline BR8260-7-3-1-1B1 & $2.0 \pm 1.4$ & $4.3 \pm 2.2$ & $4.3 \pm 1.15$ & 3.6 \\
\hline BR8261-19-1-1-3 & $3.0 \pm 2.8$ & $6.0 \pm 1.1$ & $2.3 \pm 1.15$ & 3.8 \\
\hline BR8258-7-1-5-2B3 & $4.0 \pm 1.4$ & $5.2 \pm 0.9$ & $2.3 \pm 1.15$ & 3.8 \\
\hline BR8261-19-5-2-4 & $2.5 \pm 2.1$ & $5.3 \pm 1.6$ & $4.3 \pm 1.15$ & 4.1 \\
\hline A69-1 & $2.0 \pm 1.4$ & $6.0 \pm 0.6$ & $6.3 \pm 1.15$ & 4.8 \\
\hline IR 83294-9-1-3-2-3-p1 & $4.0 \pm 1.4$ & $5.2 \pm 0.7$ & $2.3 \pm 1.15$ & 3.8 \\
\hline BR7840-2-1-1-P2 & $3.5 \pm 0.7$ & $6.2 \pm 1.1$ & $4.0 \pm 1.00$ & 4.6 \\
\hline BR8253-9-3-4-3 & $2.0 \pm 1.4$ & $6.0 \pm 1.1$ & $2.3 \pm 1.15$ & 3.4 \\
\hline BR8253-46-7-2-1B1 & $3.0 \pm 0.0$ & $6.5 \pm 1.0$ & $4.3 \pm 1.15$ & 4.6 \\
\hline BR8257-10-1-1-2 & $4.0 \pm 0.0$ & $4.2 \pm 0.9$ & $2.3 \pm 1.15$ & 3.5 \\
\hline BR8258-7-1-5-2B2 & $4.5 \pm 0.7$ & $3.8 \pm 0.9$ & $2.3 \pm 1.15$ & 3.6 \\
\hline BR8260-7-3-4-1B2 & $6.0 \pm 1.4$ & $4.8 \pm 1.3$ & $4.3 \pm 1.15$ & 5.1 \\
\hline BR7988-10-4-3-2 & $4.0 \pm 0.0$ & $5.7 \pm 1.5$ & $4.3 \pm 1.15$ & 4.7 \\
\hline IR77496-31-2-1-3-1 & - & - & $3.2 \pm 1.15$ & 3.2 \\
\hline IR2266-42-6-2 & - & - & $3.4 \pm 1.53$ & 3.4 \\
\hline BR1 (Sus. ck) & $8.6 \pm 2.8$ & $9.0 \pm 0.0$ & $7.7 \pm 0.58$ & 8.4 \\
\hline BR17 (MT. ck) & - & - & $5.7 \pm 1.15$ & 5.7 \\
\hline BR18 (T. ck) & $3.0 \pm 0.0$ & $3.0 \pm 0.0$ & $4.3 \pm 1.15$ & 3.4 \\
\hline BRRI dhan28 (Sus. ck) & $7.0 \pm 2.8$ & $7.7 \pm 0.7$ & $7.3 \pm 1.15$ & 7.3 \\
\hline BRRI dhan29 (Sus. ck) & $6.0 \pm 2.8$ & - & $4.0 \pm 1.73$ & 5.0 \\
\hline BRRI dhan55 (MT. ck) & $6.0 \pm 2.8$ & - & $2.3 \pm 1.15$ & 4.2 \\
\hline
\end{tabular}

Sus. $\mathrm{ck}=$ Susceptible check, MT ck $=$ Moderately tolerant check, $\mathrm{T} . \mathrm{ck}=$ Tolerant check.

6 Biswas et al 
Table 4. Estimates of variation among 30 genotypes in different indexes for cold tolerance in rice.

\begin{tabular}{lcc}
\hline Cold tolerance index & Range & Mean \\
\hline Leaf discoloration score (1-9) & $3.2-8.4$ & 4.4 \\
Heading delay (day) & $2-12$ & 9.0 \\
Culm length reduction (\%) & $4.5-43.1$ & 17.7 \\
Spikelet fertility reduction (\%) & $48.1-88.4$ & 70.6 \\
Yield reduction (\%) & $39.1-91.8$ & 75.4 \\
Panicle exertion score (1-9) & $1-7$ & 4.6 \\
\hline
\end{tabular}

Table 5. Genotypic response to cold stress in different cold related traits of 30 breeding lines/varieties at reproductive stage.

\begin{tabular}{|c|c|c|c|c|c|}
\hline Designation & $\begin{array}{c}\text { Heading } \\
\text { delay (day) }\end{array}$ & $\begin{array}{l}\text { Culm length } \\
\text { reduction (\%) }\end{array}$ & $\begin{array}{l}\text { Panicle exertion } \\
\text { score (1-9) }\end{array}$ & $\begin{array}{l}\text { Spikelet fertility } \\
\text { reduction }(\%)\end{array}$ & $\begin{array}{c}\text { Yield } \\
\text { reduction (\%) }\end{array}$ \\
\hline BR8264-1-1-3B2-HR4 & 6 & 6.5 & 7 & 81.5 & 82.6 \\
\hline BR7840-54-3-2-1 & 12 & 24.1 & 2 & 78.6 & 88.2 \\
\hline BR7840-54-5-3-4 & 9 & 13.7 & 3 & 73.7 & 85.3 \\
\hline BR7683-30-3-3-4 & 10 & 43.1 & 7 & 61.9 & 91.1 \\
\hline BR8427-2-3-2 & 11 & 35.1 & 1 & 66.6 & 82.5 \\
\hline BR8260-16-2-3-1 & 12 & 4.5 & 7 & 70.5 & 76.9 \\
\hline BR8261-19-1-5-1 & 9 & 23.5 & 3 & 88.4 & 77.5 \\
\hline BR8331-13-3-1-3 & 5 & 17.6 & 7 & 69.9 & 81.7 \\
\hline BR8260-7-3-1-1B1 & 8 & 21.6 & 7 & 62.6 & 61.4 \\
\hline BR8261-19-1-1-3 & 7 & 24.6 & 7 & 84.6 & 90.3 \\
\hline BR8258-7-1-5-2B3 & 9 & 11.5 & 7 & 48.1 & 39.1 \\
\hline BR8261-19-5-2-4 & 7 & 5.0 & 4 & 85.8 & 91.8 \\
\hline A69-1 & 9 & 25.4 & 3 & 71.2 & 83.1 \\
\hline IR83294-9-1-3-2-3-P1 & 9 & 5.4 & 3 & 58.8 & 77.7 \\
\hline BR7840-2-1-1-P1 & 9 & 5.0 & 4 & 79.6 & 89.1 \\
\hline BR8253-9-3-4-3 & 11 & 10.4 & 7 & 69.9 & 77.3 \\
\hline BR8253-46-7-2-1B1 & 10 & 8.1 & 7 & 56.2 & 71.8 \\
\hline BR8257-10-1-1-2 & 10 & 23.5 & 3 & 72.1 & 71.6 \\
\hline BR8258-7-1-5-2B2 & 10 & 34.1 & 1 & 45.8 & 43.3 \\
\hline BR8260-7-3-4-1B2 & 11 & 25.0 & 7 & 80.1 & 82.0 \\
\hline BR7988-10-4-3-2 & 10 & 19.6 & 3 & 77.4 & 75.3 \\
\hline IR83294-9-1-3-2-3-Gaz1 & 7 & 42.9 & 1 & 66.2 & 79.1 \\
\hline IR77496-31-2-1-3-1 & 7 & 36.4 & 6 & 64.4 & 43.2 \\
\hline IR2266-42-6-2 & 8 & 27.0 & 7 & 71.1 & 87.1 \\
\hline BR1 & 12 & 38.9 & 3 & 62.1 & 50.8 \\
\hline BR17 & 10 & 15.4 & 2 & 72.8 & 84.2 \\
\hline BR18 & 2 & 12.7 & 7 & 69.1 & 68.4 \\
\hline BRRI dhan28 & 9 & 20.3 & 3 & 78.3 & 80.4 \\
\hline BRRI dhan29 & 12 & 11.9 & 7 & 76.9 & 86.1 \\
\hline BRRI dhan55 & 8 & 20.9 & 3 & 73.2 & 62.8 \\
\hline
\end{tabular}


Table 6. Agronomic performance of $\mathbf{3 0}$ breeding lines/varieties under cold stress.

\begin{tabular}{|c|c|c|c|c|c|c|}
\hline Designation & $\begin{array}{l}\text { Days to } \\
\text { heading }\end{array}$ & $\begin{array}{l}\text { Culm length } \\
(\mathrm{cm})\end{array}$ & $\begin{array}{c}\text { Panicle length } \\
(\mathrm{cm}\end{array}$ & $\begin{array}{c}\text { No. of spikelet } \\
\text { per panicle }\end{array}$ & $\begin{array}{c}\text { Spikelet } \\
\text { fertility (\%) }\end{array}$ & $\begin{array}{l}\text { Yield per } \\
\text { plant }(\mathrm{g})\end{array}$ \\
\hline BR8264-1-1-3B2-HR4 & 122 & 65.1 & 18.2 & 141 & 18.1 & 0.61 \\
\hline BR7840-54-3-2-1 & 120 & 52.0 & 19.1 & 118 & 17.0 & 0.39 \\
\hline BR7840-54-5-3-4 & 126 & 61.8 & 22.3 & 108 & 21.0 & 0.49 \\
\hline BR7683-30-3-3-4 & 127 & 56.0 & 16.6 & 108 & 29.6 & 0.76 \\
\hline BR8427-2-3-2 & 123 & 47.3 & 23.4 & 113 & 30.4 & 0.75 \\
\hline BR8260-16-2-3-1 & 134 & 50.1 & 19.7 & 163 & 20.3 & 0.66 \\
\hline BR8261-19-1-5-1 & 134 & 51.1 & 17.3 & 237 & 3.8 & 0.20 \\
\hline BR8331-13-3-1-3 & 123 & 49.0 & 19.4 & 133 & 18.5 & 0.49 \\
\hline BR8260-7-3-1-1B1 & 130 & 54.6 & 17.3 & 199 & 15.3 & 0.65 \\
\hline BR8261-19-1-1-3 & 127 & 61.9 & 17.6 & 159 & 11.8 & 0.41 \\
\hline BR8258-7-1-5-2B3 & 120 & 38.4 & 19.3 & 140 & 28.5 & 0.81 \\
\hline BR8261-19-5-2-4 & 127 & 63.7 & 19.0 & 145 & 14.0 & 0.52 \\
\hline A69-1 & 127 & 49.5 & 20.5 & 119 & 23.0 & 0.62 \\
\hline IR83294-9-1-3-2-3-P1 & 129 & 64.3 & 19.8 & 93 & 26.1 & 0.58 \\
\hline BR7840-2-1-1-P1 & 125 & 63.6 & 17.9 & 159 & 18.6 & 0.59 \\
\hline BR8253-9-3-4-3 & 127 & 59.8 & 20.8 & 185 & 17.0 & 0.63 \\
\hline BR8253-46-7-2-1B1 & 123 & 61.4 & 19.7 & 145 & 27.6 & 0.81 \\
\hline BR8257-10-1-1-2 & - & 42.1 & 16.8 & 176 & 19.6 & 0.76 \\
\hline BR8258-7-1-5-2B2 & 107 & 39.0 & 19.7 & 178 & 30.5 & 1.41 \\
\hline BR8260-7-3-4-1B2 & 142 & 55.1 & 18.8 & 151 & 10.8 & 0.43 \\
\hline BR7988-10-4-3-2 & 110 & 48.5 & 19.8 & 134 & 19.2 & 0.74 \\
\hline IR83294-9-1-3-2-3-Gaz1 & 121 & 56.0 & 19.8 & 102 & 24.3 & 0.61 \\
\hline IR77496-31-2-1-3-1 & - & 39.9 & 17.4 & 121 & 26.3 & 0.70 \\
\hline IR2266-42-6-2 & 111 & 44.7 & 20.6 & 105 & 20.1 & 0.57 \\
\hline BR1 & - & 32.0 & 16.5 & 55 & 26.4 & 0.32 \\
\hline BR17 & 102 & 71.4 & 20.7 & 183 & 19.4 & 0.74 \\
\hline BR18 & 125 & 59.8 & 21.7 & 158 & 19.7 & 0.69 \\
\hline BRRI dhan28 & 112 & 56.1 & 19.2 & 110 & 20.0 & 0.55 \\
\hline BRRI dhan29 & 122 & 50.9 & 19.7 & 123 & 18.0 & 0.53 \\
\hline BRRI dhan55 & 109 & 48.7 & 18.4 & 97 & 22.8 & 0.56 \\
\hline
\end{tabular}

\section{Molecular characterization}

Fifty SSR markers distributed over the 12 chromosomes of rice were used to characterize and discriminate 30 genotypes having differential response to cold stress at the seedling and the reproductive stage. Among 50 SSRs, thirty eight SSRs were found polymorphic. Monomorphic SSR markers were excluded from the analysis. Table 7 summarizes the results obtained from the analysis of 38 SSR markers loci across the genotypes. Out of 38 polymorphic SSRs, two markers were present on each of chromosome 4, 9 and 10, three markers on each of chromosome 2, 3, 5 and 12, four markers on each of chromosome on 7 and 11, five markers on chromosome 8, and seven markers on chromosome 1 . The SSR markers under this study was highly informative and polymorphic as evident from their polymorphism information content (PIC) values, which measures magnitude 
Table 7. Summary results of 38 SSR markers across 30 genotypes.

\begin{tabular}{|c|c|c|c|c|c|c|}
\hline Marker & Chromosome & Genetic distance $(\mathrm{cm})$ & $\begin{array}{l}\text { No. of } \\
\text { alleles }\end{array}$ & $\begin{array}{l}\text { Major allele } \\
\text { frequency }\end{array}$ & $\begin{array}{c}\text { Gene } \\
\text { diversity }\end{array}$ & PIC \\
\hline RM1282 & 1 & 0.5 & 6 & 0.43 & 0.71 & 0.67 \\
\hline RM600 & 1 & 9.5 & 7 & 0.43 & 0.72 & 0.68 \\
\hline RM595 & 1 & 15.3 & 4 & 0.68 & 0.49 & 0.44 \\
\hline RM7266 & 1 & 24.4 & 3 & 0.87 & 0.24 & 0.22 \\
\hline RM128 & 1 & 31.1 & 3 & 0.93 & 0.13 & 0.12 \\
\hline RM5362 & 1 & 41.1 & 3 & 0.93 & 0.13 & 0.12 \\
\hline RM6840 & 1 & 43.2 & 4 & 0.73 & 0.43 & 0.4 \\
\hline RM5764 & 2 & 1.6 & 4 & 0.87 & 0.24 & 0.23 \\
\hline RM290 & 2 & 10.8 & 3 & 0.72 & 0.44 & 0.4 \\
\hline RM498 & 2 & 35.4 & 3 & 0.83 & 0.29 & 0.27 \\
\hline RM523 & 3 & 1.3 & 6 & 0.63 & 0.56 & 0.54 \\
\hline RM251 & 3 & 9.9 & 3 & 0.93 & 0.13 & 0.12 \\
\hline RM186 & 3 & 28.8 & 2 & 0.97 & 0.06 & 0.06 \\
\hline RM6314 & 4 & 18.4 & 5 & 0.37 & 0.75 & 0.71 \\
\hline RM3288 & 4 & 27.3 & 4 & 0.6 & 0.56 & 0.5 \\
\hline RM1089 & 5 & 5.3 & 7 & 0.42 & 0.71 & 0.67 \\
\hline RM6024 & 5 & 17.8 & 4 & 0.78 & 0.37 & 0.35 \\
\hline RM6972 & 5 & 25.3 & 4 & 0.52 & 0.63 & 0.57 \\
\hline RM7454 & 7 & 1.1 & 3 & 0.6 & 0.55 & 0.48 \\
\hline RM6574 & 7 & 4.7 & 2 & 0.83 & 0.28 & 0.24 \\
\hline RM21333 & 7 & 9.0 & 3 & 0.73 & 0.41 & 0.35 \\
\hline RM5847 & 7 & 23.6 & 9 & 0.27 & 0.84 & 0.83 \\
\hline RM5911 & 8 & 0.1 & 5 & 0.57 & 0.61 & 0.56 \\
\hline RM3215 & 8 & 8.6 & 6 & 0.4 & 0.69 & 0.64 \\
\hline RM22780 & 8 & 10.8 & 5 & 0.37 & 0.72 & 0.68 \\
\hline RM22870 & 8 & 13.9 & 9 & 0.27 & 0.84 & 0.82 \\
\hline RM556 & 8 & 22.2 & 3 & 0.9 & 0.18 & 0.18 \\
\hline RM5799 & 9 & 3.8 & 2 & 0.87 & 0.23 & 0.2 \\
\hline RM3769 & 9 & 11.7 & 3 & 0.43 & 0.64 & 0.56 \\
\hline RM311 & 10 & 9.7 & 5 & 0.4 & 0.7 & 0.65 \\
\hline RM258 & 10 & 17.8 & 5 & 0.4 & 0.66 & 0.6 \\
\hline RM286 & 11 & 0.4 & 3 & 0.7 & 0.46 & 0.41 \\
\hline RM3701 & 11 & 8.1 & 2 & 0.93 & 0.12 & 0.12 \\
\hline RM5349 & 11 & 19.2 & 5 & 0.3 & 0.76 & 0.72 \\
\hline RM6094 & 11 & 28.4 & 3 & 0.57 & 0.58 & 0.51 \\
\hline RM511 & 12 & 17.4 & 2 & 0.77 & 0.36 & 0.29 \\
\hline RM313 & 12 & 20.8 & 5 & 0.63 & 0.55 & 0.51 \\
\hline RM6410 & 12 & 29.3 & 5 & 0.53 & 0.64 & 0.59 \\
\hline Total & & & 161 & & & \\
\hline Mean & & & 4 & 0.64 & 0.47 & 0.44 \\
\hline
\end{tabular}


of polymorphism and diversity among the genotypes for a marker locus used in linkage analysis. The PIC values varied greatly for all 38 SSR loci ranging from 0.06 to 0.83 with an average of 0.44 . The highest PIC value (0.83) was obtained for RM5847 followed by RM22870 (0.82), RM5349 (0.72), RM6314 (0.71), RM600 (0.68), RM1282 (0.67) and RM1089 (0.67). A total of 161 alleles across 30 genotypes were detected at 38 SSR loci. The number of alleles generated by each marker locus varied from 2.0 to 9.0 with an average value of 4.0 . The highest number of alleles (9.0) was detected with RM22870 and RM5847, and the lowest number of alleles (2.0) was detected with RM511, RM5799, and RM3701and RM186. On average $64 \%$ of the genotypes shared a common major allele at any given locus ranging from 27\% (RM22870) to 97\% (RM186) common allele per marker locus. An overall genetic diversity of 0.47 with a range of 012 to 0.84 was obtained among the breeding lines/varieties. The gene diversity of each SSR locus appeared to be associated with the number of alleles detected per locus.

The UPGMA-based dendrogram obtained from the binary data deduced from DNA profiles of the samples showed that the genotypes which were derivatives of genetically similar types clustered together (Fig. 1). All genotypes clearly grouped into two major clusters in the dendrogram at $68 \%$ genetic similarity based on Nei similarity index with additional sub-clusters in each group. ClusterI contained three genotypes which shared $76 \%$ common alleles and further divided into two sub-clusters at 0.84 similarity coefficient. Twenty-seven genotypes were grouped into Cluster-II, which was further divided into two sub-clusters. BR18, the cold tolerant variety at the seedling stage was grouped singly in one sub-cluster, while the remaining 26 genotypes including cold susceptible BR1, BRRI dhan28 and BRRI dhan29 were grouped in another subcluster, which was further divided into many sub-groups. In these subgroups $79.25 \%$ common alleles were shared by 19 genotypes. BR18 shared $73.5 \%$ common alleles with the genotypes in Cluster-II. However, the genotypes in Cluster - I belonging 76\% common alleles had $28 \%$ different alleles from BR18 of Cluster - II. The coaxial tree based on neighbour joining algorithm also showed that the genotypes in Cluster - I were genetically closer to BR18 than others (Fig. 2).

\section{DISCUSSION}

Rice plants are affected by cold stress at various stages of crop growth depending on severity and extent of cold wave (Li et al., 1981). The sensitivity to cold stress varies between the stages of crop growth in rice. Yoshida (1981) showed that rice plants have a lower threshold temperature $\left(10-13^{\circ} \mathrm{C}\right)$ for cold damage during the early stages of development (germination and vegetative), while threshold temperature for damage is higher $\left(18-20^{\circ} \mathrm{C}\right)$ during the reproductive stage. Thus, vegetative stages are less sensitive to cold than the reproductive stage. Despite these differences among stages, cool weather and cold irrigation water can damage the rice plants during any developmental stage such as germination, seedling, vegetative, reproductive and maturity (Majumder et al., 1989; Andaya and Mackill, 2003; Xu et al., 2008, Ye et al., 2009). The most common symptoms of LTS damage at the germination stage are delayed and lower percentage of germination (da Cruz and Milach, 2000). At the vegetative stage, cold damage is expressed through yellowing of the leaves, shorter stature and decreased tillering of rice plants. Cold stress at the reproductive stage commonly causes spikelet sterility; incomplete panicle exertion and spikelet abortion also may occur (Satake and Hayase, 1970), which ultimately lower the grain yield of rice. Therefore, leaf discoloration, \% survivability and \% recovery are considered as the three major criteria for 


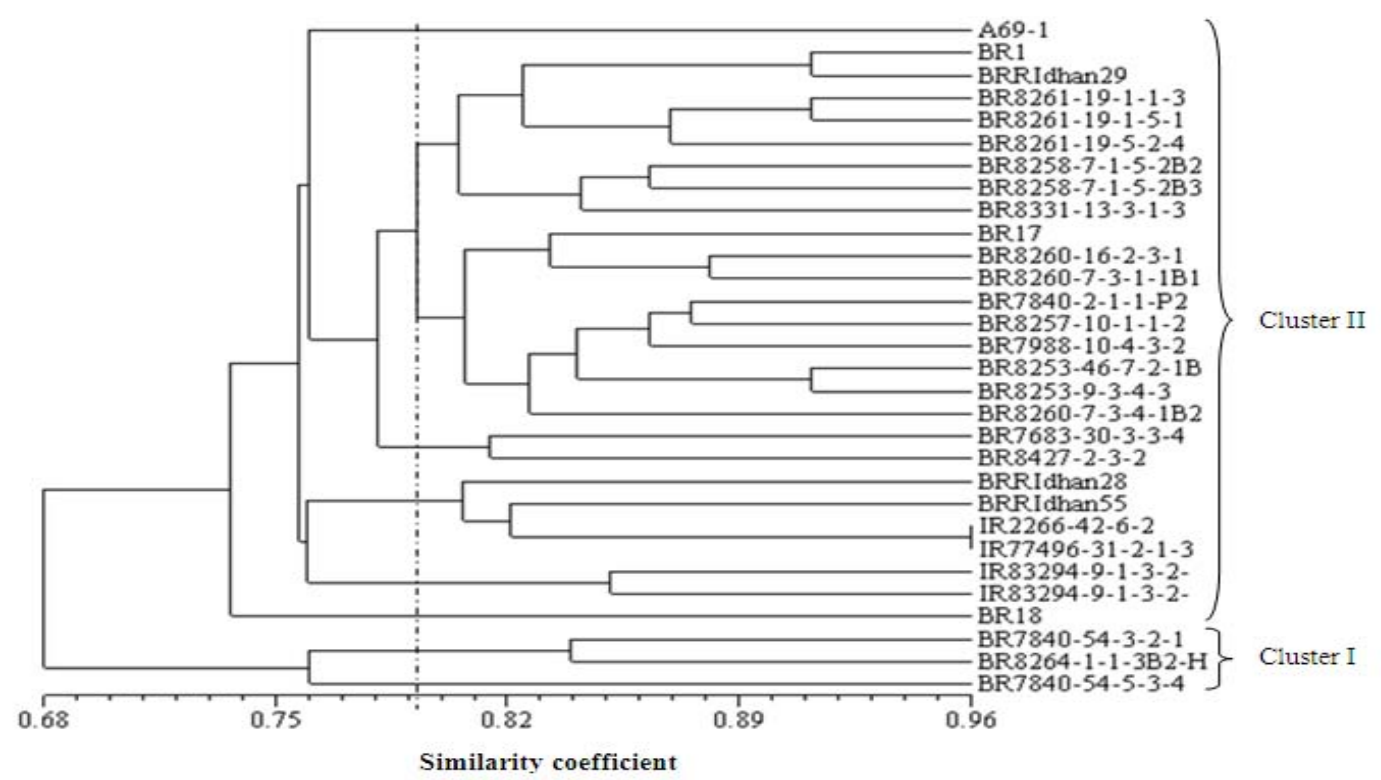

Fig. 1. Cluster of 30 rice genotypes based on Nei similarities index calculated from allele frequency data matrix of 38 SSR markers using UPGMA dendrogram.
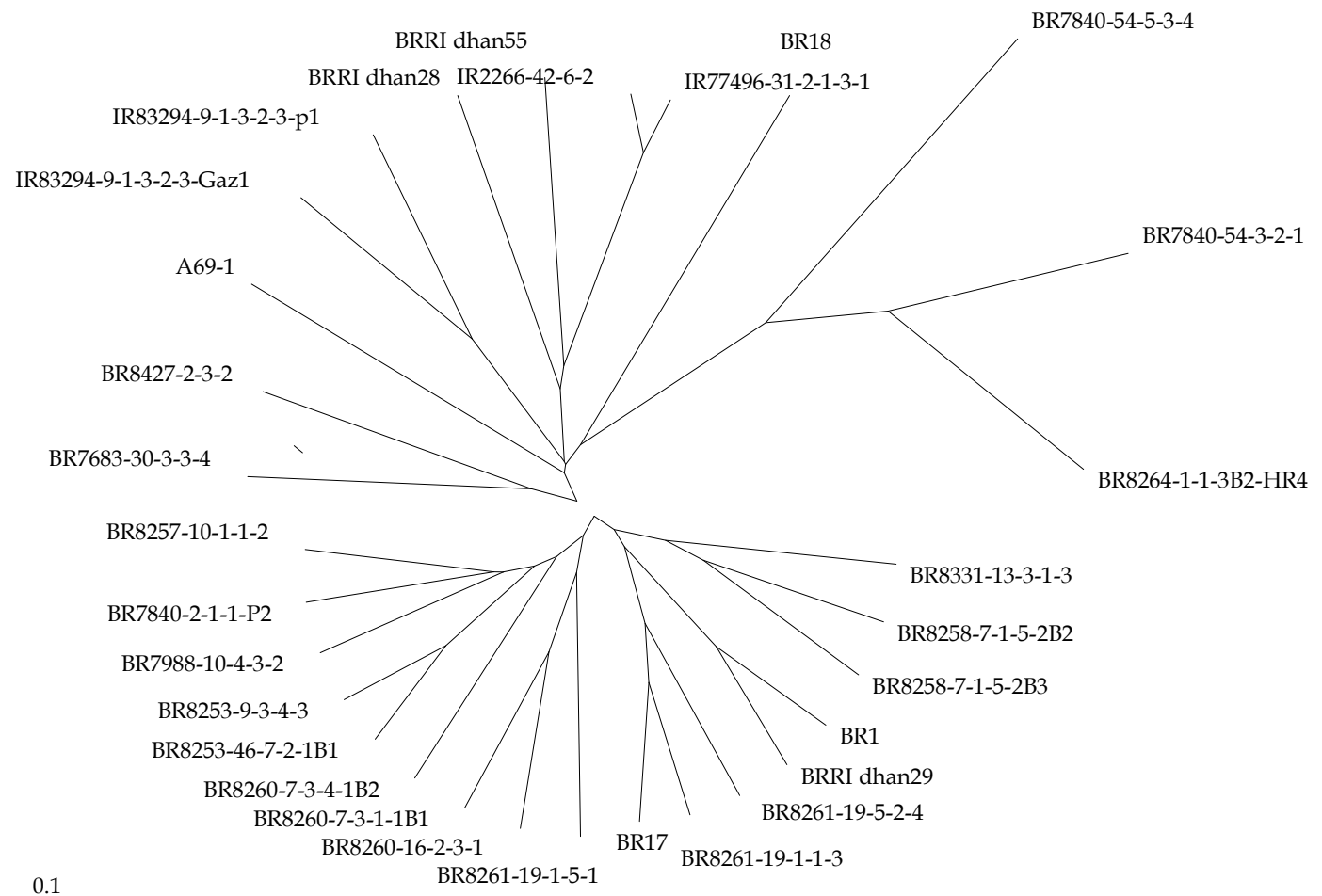

Fig. 2. Cluster of 30 rice genotypes based on allele sharing similarities index calculated from data matrix of 38 SSR markers using neighbour joining algorithm. 
determining the level of cold tolerance at seedling stage in rice (NICS, 2004). While, spikelet fertility $\%$ and grain yield are considered to be selection criteria for reproductive stage cold tolerance.

In this study, we measure LD score for discriminating varieties or germplasm under cold stress. LTS of $13^{\circ} \mathrm{C}$ at 3-leaf stage to an initial population of 594 breeding lines showed well discrimination among themselves in leaf discoloration. The 22 breeding lines obtaining LD score $(1-3)$ in the initial evaluation along with three susceptible check varieties, five tolerant check varieties showed wide range of variation in the LD score starting from 3.2 to 8.4. The variations were wider and more pronounced in the Batch 1 and Batch 2 ranging from 2 to 8.6 and 3.0 to 9.0, respectively (Table 3). In all three batches, the tolerant variety (BR18) and susceptible variety (BR1) obtained an average LD score of 3.4 and 8.4, respectively. The lowest average LD score was obtained with IR77496-31-2-1-3-1 (3.2) followed by IR2266-42-6-2 (3.4), BR8257-10-1-12 (3.5) indicating them to be strong cold tolerant at the seeding stage. Among the 30 genotypes evaluated in the final evaluation, twelve showed LD score less than 4 and other 12 genotypes showed LD values ranging from 4.0 to 5.0 , indicating them to be tolerant and moderately tolerant, respectively. It is important to note that the majority of breeding lines which showed low LD values were derived from the crosses that involved at least one parent originated from a single cross BR7166, which was developed from a cross between BRRI dhan29 and a Chinese genotype, PL Youhong (Table 1). This finding indicated that the alleles from PL Youhong might have contribution for cold tolerance in the breeding lines.

Cold stress has noticeable consequence on reproductive stage as it induces spikelet sterility due to low seed setting, which ultimately turns into low yield of rice (Thakura et al., 2010). Jena et al. (2010) also reported that cold stress not only affects spikelet fertility but also reduces culm length and delays heading. In this study most of all breeding lines showed higher reduction percentage in spikelet fertility and grain yield except BR8258-7-1-5-2B2 and BR8258-7-1-5-2B3 (Table 5). Ye et al. (2009) and Shinada et al. (2013) also reported similar results of yield reduction under cold stress at the reproductive stages. Low temperature significantly affects yield attributing traits such as culm length, number of panicles, reduce panicle emergence and panicle length, and grain yield in rice genotypes (Ghadirnezhad et al., 2004 and Farrell et al., 2006). In this study, spikelet fertility and grain yield were relatively lower in all breeding lines including the check varieties (Table 6). BR1, the cold susceptible variety showed comparatively lower reduction in spikelet fertility and grain yield on the other hand, the breeding lines/varieties showing higher tolerance to cold stress at seedling stage had higher reduction in spikelet fertility and grain yield except few cases, like BR8258-7-1-52B2, BR8258-7-1-5-2B3, etc. which indicated the independence of genes underlying cold tolerance at seedling stage and reproductive stage. Biswas et al. (2019) also reported that genes or QTL conferring cold tolerance for different growth stages are independent but they might be co-localized in some cases. The seedling stage cold tolerant variety, BR18 (LD: 3.4) also showed relatively higher reduction in spikelet fertility and grain yield under cold stress at booting stage compared to the plants grown under ambient temperature. Relative comparison of cold sensitivity among the genotypes suggests that the genetic control on cold tolerance at both seedling and reproductive stage is absent in the test genotypes rather seedling stage cold tolerance is dominant except few cases (Tables 3, 5 and 6).

The UPGMA dendrogram based on Nei similarity index of shared SSR loci among the genotypes also showed that majority of the breeding lines showing 4-5 degrees of LD were grouped together. However, susceptible 
varieties, BR1, BRRI dhan28 and BRRI dhan29 shared $76 \%$ to $84 \%$ common alleles with these genotypes. Two breeding lines, BR8258-7-1-52B2 and BR8258-7-1-5-2B3 originating from a three way cross that involved BRRI dhan 29 as one of the three parents had $86 \%$ common alleles and showed cold tolerance at both seedling and reproductive stage. Another breeding line, BR8331-13-3-1-3 which was genetically very close to BR8258-7-1-5-2B2 and BR8258-7-1-5-2B3 had only 2\% different alleles from them and showed around $70 \%$ and $82 \%$ reduction in spikelet fertility and grain yield, respectively. These results indicated that the SSR loci, which contributed to this difference between the two cold tolerant breeding lines (BR8258-7-1-5-2B2 and BR8258-7-1-5-2B3) and the cold susceptible BR8331-13-3-1-3, might have close association with the QTL responsible for the increased seed setting rate and grain yield under cold stress. The binary data of the shared alleles of the SSR (Table 8) showed difference in seven loci (RM1282, RM600, RM5349, RM6972, RM5847, RM5911, and RM511), which indicated these seven SSR makers might be useful in discriminating tolerant lines from susceptible ones for higher seed setting rate under cold stress. A distinction between the tolerant and susceptible breeding lines in both phenotyping and molecular analysis indicates the presence of specific alleles that could be useful for the improvement of cold tolerance in rice.

\section{CONCLUSION}

Three breeding lines, BR8253-9-3-4-3, IR7749731-2-3-1and IR2266-42-6-2 demonstrated higher cold tolerance only for the seedling stage (LD score <3.0), while two breeding lines, BR8258-7-1-5-2B2 and BR8258-7-1-5-2B3 having $86 \%$ shared alleles showed cold tolerance both at seedling stage and reproductive stage in terms of low reduction in spikelet fertility $(45.8 \%$ and $48.1 \%)$ and grain yield $(43.3 \%$ and $39.1 \%)$. In addition, eight SSR loci showed differential allele call between the cold tolerant and susceptible genotypes at reproductive stage. The identified breeding lines and SSR markers in this study could be useful for developing cold tolerant rice.

Table 8. Binary values of allele distribution among 30 rice breeding lines/varieties deduced from DNA profiling of seven SSR loci showing allelic variation between BR8258-7-1-5-2B2 and/or BR8258-7-1-5-2B3 and BR8331-13-3-1-3.

\begin{tabular}{|c|c|c|c|c|c|c|c|c|c|c|c|c|c|c|c|c|c|c|c|c|c|c|c|c|c|c|c|c|c|c|c|}
\hline \multirow[b]{2}{*}{ SSR Loci } & & \multicolumn{30}{|c|}{ Genotype } \\
\hline & 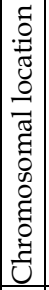 & $\begin{array}{l}\text { 尚 } \\
\text { ơ }\end{array}$ & $\frac{\vec{c}}{\underline{\underline{N}}}$ & $\begin{array}{l}\vec{\partial} \\
\underline{\underline{\nu}} \\
\underline{\underline{n}}\end{array}$ & $\begin{array}{l}\infty \\
\underset{\sim}{\vec{m}} \\
\end{array}$ & $\begin{array}{l}+1 \\
\infty \\
\infty \\
0 \\
0 \\
\infty \\
\infty \\
\infty \\
0 \\
\hat{D} \\
\hat{D}\end{array}$ & 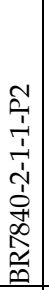 & 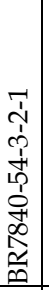 & 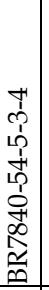 & 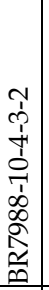 & 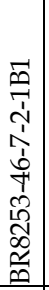 & 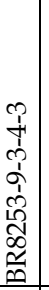 & 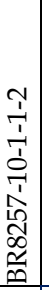 & 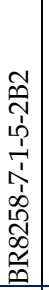 & 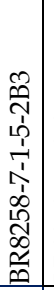 & 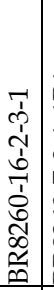 & 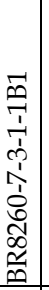 & 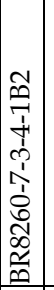 & 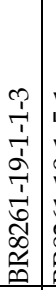 & 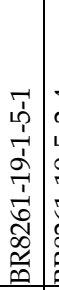 & 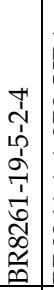 & 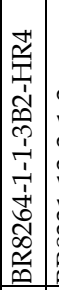 & 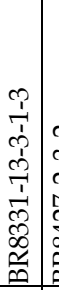 & 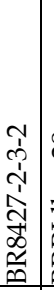 & 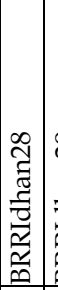 & 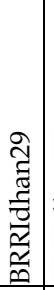 & 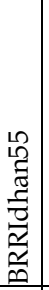 & 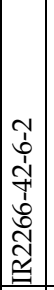 & 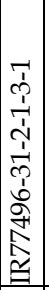 & 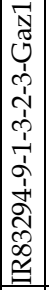 & 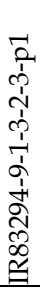 \\
\hline RM1282 & 1 & 0 & 0 & 0 & 0 & 0 & 1 & 0 & 0 & 0 & 0 & 0 & 0 & 1 & 1 & 0 & 0 & 0 & 0 & 0 & 0 & 0 & 0 & 0 & 0 & 0 & 0 & 1 & 1 & 1 & 1 \\
\hline RM600 & 1 & 0 & 0 & 0 & 0 & 0 & 0 & 0 & 0 & 0 & 0 & 0 & 1 & 1 & 1 & 0 & 0 & 0 & 0 & 0 & 0 & 0 & 0 & 0 & 0 & 0 & 0 & 0 & 0 & 0 & 0 \\
\hline RM5349 & 3 & 0 & 1 & 0 & 0 & 1 & 0 & 0 & 0 & 0 & 0 & 0 & 0 & 1 & 1 & 0 & 0 & 0 & 1 & 1 & 1 & 0 & 0 & 1 & 0 & 1 & 0 & 0 & 0 & 0 & 0 \\
\hline RM6972 & 5 & 0 & 1 & 1 & 1 & 0 & 1 & 0 & 1 & 1 & 1 & 1 & 1 & 1 & 1 & 0 & 1 & 1 & 1 & 0 & 1 & 0 & 0 & 0 & 0 & 0 & 0 & 0 & 0 & 0 & 1 \\
\hline RM5847 & 7 & 0 & 1 & 0 & 0 & 0 & 0 & 0 & 0 & 0 & 0 & 0 & 0 & 1 & 1 & 0 & 0 & 0 & 1 & 1 & 1 & 0 & 0 & 0 & 0 & 1 & 0 & 0 & 0 & 0 & 1 \\
\hline RM5911 & 8 & 1 & 0 & 0 & 0 & 0 & 0 & 0 & 0 & 0 & 0 & 0 & 0 & 1 & 1 & 0 & 0 & 0 & 0 & 0 & 0 & 1 & 0 & 0 & 0 & 0 & 1 & 0 & 0 & 0 & 0 \\
\hline RM511 & 12 & 0 & 0 & 0 & 0 & 0 & 0 & 0 & 0 & 0 & 0 & 0 & 0 & 1 & 1 & 0 & 0 & 0 & 0 & 0 & 0 & 1 & 0 & 0 & 0 & 0 & 0 & 1 & 1 & 1 & 1 \\
\hline
\end{tabular}




\section{ACKNOWLEDGEMENT}

The authors are thankful to the Integrated Agricultural Productivity Project, BRRI Part for partial funding of the study. The authors also acknowledge Md Shariful Islam, SA, Plant Breeding Division and Nomita Das, MS student, Jahangirnagar University for their assistance in the field and laboratory work.

\section{REFERENCES}

Andaya, V C and T H Tai. 2006. Fine mapping of the qCTS12 locus, a major QTL for seedling cold tolerance in rice (Oryza sativa L.). Theor. Appl. Genet., 113: 467-475.

Andaya, V C and T H Tai. 2007. Fine mapping of the qCTS4 locus associated with seedling cold tolerance in rice (Oryza sativa L.). Mol. Breed., 20: 349-358.

Andaya, V C. and D J Mackill. 2003. Mapping of QTLs associated with cold tolerance during the vegetative stage in rice. J. Exp. Bot., 54: 2579-2585.

Anderson, J A, G A Churchil, J E Autrique, S O Tanksley and M E Sorrels. 1993. Optimizing parent selection for genetic linkage maps. Genome, 36: 181-186.

Baruah, A R, N Ishigo-Oka, M Adachi, Y Oguma, Y Tokizono, K Onishi and Y Sano. 2009. Cold tolerance at the early growth stage in wild and cultivated rice. Euphytica, 165:459-470.

BRRI 2013. BRRI Annual Report 2012-13. Bangladesh Rice Research Institute Gazipur-1701, Bangladesh, Pp. 334.

Biswas, P S, M M Rashid, H Khatun, R Yasmeen and J K. Biswas. 2019. Scope and Progress of Rice Research Harnessing Cold Tolerance. In: Hasanuzzaman M, M Fujita, K Nahar and J K Biswas (eds) Advances in Rice Research for Abiotic Stress Tolerance. (Chapter 11): 225 - 264.

Biswas, P S, H Khatun, N Das, M M Sarker and M Anisuzzaman. 2017. Mapping and validation of QTLs for cold tolerance at seedling stage in rice from an indica cultivar Habiganj Boro VI (Hbj. BVI). 3 Biotech, 7(6): 359.

da Cruz, R P and S C K, Milach. 2000. Breeding for cold tolerance in irrigated rice. Ciencia Rural, 30:909917.

Dice, L R. 1945. Measures of the amount of ecologic association between species. Ecology, 26(3): 297302.

Farrell, C, K M Fox, R L Williams, S Fukai. 2006. Genotypic variation for cold tolerance during reproductive development in rice: Screening with cold air and cold water. F. Crop. Res., 98(2-3):178-194.
Ghadirnezhad, R and A Fallah. 2014. Temperature effect on yield and yield components of different rice cultivars in flowering stage. Int. J. Agron., 1-4.

Han, L Z, Y L Qiao, G L Cao, Y Y Zhang, Y P An, J D Ye and H J Koh. 2004. QTLs analysis of cold tolerance during early growth period for rice. Rice Sci., 11: 245-250.

Han, L Z, Y L Qiao, S Y Zhang, Y Y Zhang, G L Cao, J Kim, $\mathrm{K}$ Lee and $\mathrm{H}$ Koh. 2007. Identification of quantitative trait loci for cold response of seedling vigour traits in rice. J. Genet. Genomics, 34: 239246.

Hospital, F. 2009. Challenges for effective marker-assisted selection in plants. Genetica., 136: 303-310.

Iwata, N, H Shinada, H Kiuchi, T Sato and K Fujino. 2010. Mapping of QTLs controlling seedling establishment using a direct seedling method in rice. Breeding Sci., 60: 353-360.

Jena K K, S M Kim, J P Suh, Y J Kim. 2010. Development of cold tolerant breeding lines using QTL analysis in rice. In: Second African Rice Congress, Bamako, Mali. Pp. 22-26,

Ji, Z J, Y X Zeng, D L Zeng, L Y Ma, X M Li, B X Liu and C D Yang. 2010. Identification of QTLs for rice cold tolerance at plumule and 3-leaf-seedling stages by using QTL Network software. Rice Sci., 17: 282-287.

Kabir, M S, M Howlader, J K Biswas, M A A Mahbub and M N E Elahi. 2015. Probability of Low Temperature Stress at Different Growth Stages of Boro Rice. Bangladesh Rice J., 19(2): 19-27.

Khatun, H, P S Biswas, H G Hwang and K M Kim. 2016. A Quick and Simple In-house Screening Protocol for Cold-Tolerance at Seedling Stage in Rice. Plant Breed. Biotechnol., 4(3): 373-378.

Kim, S M, J P Suh, C K Lee, C J H Le, Y G Kim K K Jena. 2014. QTL mapping and development of candidate gene-derived DNA markers associated with seedling cold tolerance in rice (Oryza sativa L.). Mol.Genet. Genom., 289(3): 333-343.

Jiang, L, M M Xun, J K Wang and J M Wan. 2008. QTL analysis of cold tolerance at seedling stage in rice (Oryza sativa L.) using recombination inbred lines. J. Cereal Sci., 48:173-179.

Li, T G, R M Visperas and B S Vergara. 1981. Correlation of cold tolerance at different growth stages in rice. Acta Bot. Sin., 23: 203-207.

Liu, K and S V Muse. 2005. Power Marker: Integrated analysis environment for genetic marker data. Bioinformatics, 21: 2128-2129.

Lou, Q J, L Chen, Z X Sun, Y Z Xing, J Li, X Y Xu, H W Mei and L J Luo. 2007. A major QTL associated with cold tolerance at seedling stage in rice (Oryza sativa L.). Euphytica, 158: 87-94.

Mackill, D J and X M Lei. 1997. Genetic variation for traits related to temperate adaptation of rice cultivars. Crop Sci., 37:1340-1346. 
Maclean, J L, D C Dawe, B Hardy and G P Hettel (ed.). 2002. Rice Almanac, Los Baños (Philippines): International Rice Research Institute, Bouaké (Côte d'Ivoire): West Africa Rice Development Association, Cali (Colombia): International Center for Tropical Agriculture, Rome (Italy): Food and Agriculture Organization.

Majumder, M K, D V Seshu and V V Shenoy. 1989. Implications of fatty acids and seed dormancy in a new screening procedure for cold tolerance in rice. Crop Sci., 29: 1298-1304.

Misawa, S, N Mori, S Takumi, S Yoshida and C Nakamura. 2000. Mapping of QTLs for low-temperature response in seedlings of rice (Oryza sativa L.). Cereal Res. Commun., 28: 33-40.

Nei, $\mathrm{M}$ and $\mathrm{N}$ Takezaki. 1983. Estimation of genetic distances and phylogenetic trees from DNA analysis. Proc. 5th World Cong. Genet. Appl. Livestock Prod., 21: 405-412.

NICS (National Institute of Crop Science). 2004. Stress tolerance breeding of rice in Korea. National Institute of Crop Science, Rural Development Administration. The Republic of Korea. Pp. 111.

Qian, Q, D L Zeng, P He, X W Zheng, Y Chen and L H Zhu. 2000. QTL analysis of the rice seedling cold tolerance in a double haploid population derived from anther culture of a hybrid between indica and japonica rice. Chin. Sci Bull., 45: 448-453.

Rashid, M M, and R Yasmeen. 2017. Cold injury and flash flood damage in Boro rice cultivation in Bangladesh: a review. Bangladesh Rice J., 21(1):1325.

Rohlf, F J. 2002. Geometric morphometrics and phylogeny. Systematics Association Special Volume, 64: 175-193

Ribaut, J M and D Hoisington. 1998. Marker-assisted selection: new tools and strategies. Trends Plant Sci., 3: 236-239.

Salina, E, O Dobrovolskaya, T Efremova, I Leonova and M $S$ Roder. 2003. Microsatellite monitoring of recombination around the Vrn-B1 locus of wheat during early backcross breeding. Plant Breed., 122: 116-119.

Saito, K, Y H Saito, M Kuroki, Y Sato. 2010. Map-based cloning of the rice cold tolerance gene Ctb1. Plant Sci., 179: 97-102.
Satake, T and H Hayase. 1970. Male sterility caused by cooling treatment at the young microspore stage in rice plants: V. Estimations of pollen developmental stage and the most sensitive stage to coolness. Japanese J. of crop Sci., 39 (4): 468-473.

Shinada H, N Iwata, S Takashi, F Kenji. 2013. Genetical and morphological characterization of cold tolerance at fertilization stages in rice. Breeding Sci., 63: 179-204.

Sun, J, L Yang, J Wang, H Liu, H Zheng, D Xie, M Zhang, $M$ Feng, $Y$ Jia, $H$ Zhao and $D$ Zou. 2018. Identification of a cold-tolerant locus in rice (Oryza sativa L.) using bulked segregant analysis with a next-generation sequencing strategy. Rice, 11: 24. https:/ / doi.org/10.1186/s12284-018-0218-1

Thakura P, S Kumara, J A Malika, J D Bergerb, H Nayyara. 2010. Cold stress effects on reproductive development in grain crops: An overview. Environ. Exp. Bot., 67: 429-443.

Unkovich, M. 2008. Global Issues, Paddock Action. In: Proceedings of the 14th Australian Agronomy Conference, 21-25 September 2008, Adelaide, South Australia.

Virk, P S, B V Ford-Lloyd, M T Jackson and H J Newbury. 1995. Use of RAPD for the study of diversity within plant germplasm collections. Heredity, 74(2): 170179.

Xu, L, M L Zhou, Y W Zeng, F M Wang, H L Zhang, S Q Shen and Z C Li. 2008. Identification and mapping of quantitative trait loci for cold tolerance at the booting stage in a japonica rice near-isogenic line. Plant Sci., 174(3): 340-347.

Ye C, S Fukai, D I Godwin, R Reinke, P Snell, J Schiller, J Basnayake. 2009. Cold tolerance in rice varieties at different growth stages. Crop and Pasture Sci., 60: 328-338.

Yoshida, S. 1981. Fundamentals of rice crop science. International Rice Research Institute, Los Banos. Manila. Pp. 1-63.

Zhang, Z H, L Su, W Li, W Chen and Y G Zhu. 2005. A major QTL conferring cold tolerance at the early seedling stage using recombinant inbred lines of rice (Oryza sativa L.). Plant Sci., 168: 527-534. 